\title{
Determinants of Consumers' Perceived Experience Value in Relation to Online Organic Food Purchase
}

\author{
Sanjukta Ghosh \\ School of Design Business and Technology, Srishti Institute of Art Design and Technology, India
}

Received December 21, 2019; Revised February 29, 2020; Accepted March 12, 2020

Copyright $\odot 2020$ by authors, all rights reserved. Authors agree that this article remains permanently open access under the terms of the Creative Commons Attribution License 4.0 International License

\begin{abstract}
Organic food buying behavior is high involvement purchase and related to consumers' deeper value system. The decision-making is quiet complex due to its high price and lack of trustworthiness. Therefore, there is a need for separate and more engaging shopping platform, which can co-create a delightful and enjoyable shopping experience for the consumers. Literature does not give a clear understanding about the factors which can influence Consumers' Perceived Experience Value (CPEV). Hence the study aims to identify the drivers or the determinants of CPEV in relation to online organic food purchase. The objectives of this study are to identify the domain of constructs along with their respective items for $\mathrm{CPEV}$ and their relation through qualitative exploration and validate the items for respective construct through Exploratory and Confirmatory Factor Analys is. The study contributes a scale which can measure the constructs like Cognitive Engagement, Emotional Engagement, Behavioral Engagement, Telepresence, Willingness to co-create, Willingness to pay for Experience and Ease of Use in relation to online organic food purchase which was not available in the existing literature. This will be beneficial for the organic food producers to develop a digital marketing strategy and penetrate the market. The study will also help the service and experience designers to explore these opportunities and create a platform for the small-scale farmers and contribute in their livelihood development.
\end{abstract}

Keywords Organic Food, Experience Value, Grounded Theory, Affinity Diagramming, Scale Development

\section{Introduction}

The decision around organic food purchase is as sociated to a deeper value system of the consumers' involving logical and intellectual reasoning (Tarkiainen and Sundqvist, 2009) and complicated selection process as the price is high and low trustworthiness (Lavin et al., 2015). Studies show that organic food purchase is considered to be a high involvement decision-making where economic considerations and trustworthyness plays a significant role (Ghosh et. al., 2019). The adoption of organic food is not so satisfactory when marketed with conventional food. Therefore, there is a need for separate and more engaging shopping platform, which can co-create a delightful and enjoyable shopping experience for the consumers. Hence the study aims to identify the drivers or the determinants of Consumers' Perceived Experience Value in relation to online organic food purchase.

Experience value is explained in the literature as a language which exp lains "interactive relativis tic pre ference experience" (Holbrook 1999). This lead by Holbrook's have been adopted in many studies where exploration and testing of this value construct has been done in different marketing situations (Prebensen et al, 2013; Woodall 2003; Sweeney and Soutar 2001). On the other hand, Perceived value has been extensively recognised in various literature related to marketing theories in order to understand consumer behavior (Nilson 1992; Ostrom and Iacobucci 1995) and consumer perceived value (Woodruff, 1997) as "a customer's perceived preference for and evaluation of product or service attributes and their performances, and consequences arising from use that facilitate (or block) achieving the customer's goals and purposes in use situations." Perceived experience value has also been outlined and tested in various context like hospitality (Al-Sabbahy et. al 2004; Kashyap and Bojanic 2000); in heritage tourism (Chen and Chen 2010), cruise experiences (Du mand and Mattila 2005; Petrick 2004). However, there is not much work has been done in the context of Organic Food Purchase.

Literature shows that consumers' response to a website or any other platform mediated by dig ital technology which comprises of four experiential states. They are consumer 
engagement, perceived interactivity and ease of use, participation or co-creation and telepresence (Hollebeek, 2011b). Telepresence is a mental state of being present in an environment of a situation mediated by computers or other digital media (Mollen \& Wilson, 2010). Easy to purchase is one of the key driver to create a better shopping experience for the consumers (Brodie et al., 2011). The concept of Consumer Engagement has a multi-dimensional approach which is based on stakeholders' specific manifestation of relevant emotional, cognitive and behavioraldimensions which are interactive and co-created through consumer experience (Hollebeek, 2011a, Groeger et. al., 2016). So et al. (2014) in the study mentioned that by and large consumer engagement has been a theoretical discourse, with very little empirical backing for the development of theory. Also the literature does not give a clear understanding about the factors which can influence Consumers' Perceived Experience Value (CPEV). Hence there is also a need to identify the factors and the relevant ite ms to measure CPEV. Therefore, the study aims to focus on theory development in the area of consumer engagement and consumers perceived experience value in relation to online organic food shopping. The relevant research questions for this study are as follows.

\subsection{Research Questions}

1. What determines Consumers' Perceived Experience Value $(\mathrm{CPEV})$ in relation to Online Organic Food Purchase?

2. What drives the consumers to engage with an online organic food brand?

\subsection{Research Objective}

The researcher felt a need for concept development through qualitative exploration rather than merely testing the existing concepts. Therefore, the study was conducted through a combination of qualitative and quantitative research. The following research objectives are

i). Identify the domain of constructs for CPEV and their relation through qualitative exploration.

ii). Identify the items for each of the construct through qualitative exploration.

iii). Validate the items for respective construct through quantitative technique.

\section{Research Method}

The researcher in this study had worked on to identify the related domain of constructs pertaining to consumers' perceived experience value through qualitative exploration.

\subsection{Qualitative Research Method}

Depth interview was conducted through convenience and judgmental sampling. The criteria to select the samples were regular organic food consumer and regular online shopper. The consumers were selected from three organic stores in Bangalore who were ready to spare 20-30 minutes for the interview. 10 such interviews were conducted. The interviews were recorded and the transcripts were used for qualitative research. Some open-ended questions which were administered during the depth interview with the respondents.

1. What do you think is the major barrier of organic food purchase?

2. How can we create an experience, which will make online organic food more trustworthy?

3. What are the information you should be looking for in a online organic store?

Grounded Theory and affin ity diagramming was used as a tool for Qualitative Research.

\subsubsection{Grounded Theory (GT)}

Grounded Theory was first proposed by Glaser and Strauss (1967) under the domain of social science research This is also an organized and appropriate approach in generating items and cluster them to different dimensions (Parry, 2003). The researcher continued the analys is of the interview-transcripts till it was felt to reach a saturation level along the dimensions and no new items or were getting generated. Grounded Theory is executed through three phases. The first phase is open coding which is considered to be the most intensive phase. This is followed by axial coding and selective coding. Below is an excerpt from the transcript of the depth interview conducted to understand cognitive engagement of consumers with online organic food purchase.

"It is difficult to belief the organic produce and their claim. I will prefer to associate and feel more trustworthy with an organic brand, which better connects me with the farmers. An online platform where the source of fruits and vegetables can be tracked which will make their produce more trustworthy. I want to get more information about the nutritional value of fruits and vegetables and also local food recipe. Most of the time we don't know how to cook it."

\subsubsection{Open Coding}

Here the respondent mentioned about those characteristics of online organic food purchase which might cause better consumer engagement and consumers' perceived experience value. Open coding on the data was conducted in this study to identify multiple underlying concepts, which are also known as labeled phenomena or primary label (Goulding, 2002). The primary labeling was done on the basis of researcher's understanding in relation to its significance in the data.

- More trustworthy with better connectivity with the farmers. 
- $\quad$ More trustworthy if source of vegetables and fruits can be tracked.

- More information about nutritional value of fruits and vegetables.

- More information about local recipe.

The researcher coded "More trustworthy with better connectivity with the farmers" because the respondents felt that this can make them more engaged with the organic brand and can create better experience by giving a sense of connectedness with the farmers and easy to belief the product. Similarly, "More trustworthy if source and vegetables and fruits" can be tracked was coded because the respondents felt that this cerate more cognitive engagement with the organic brand and can create better experience by more transparent process. The next two codes or labels are "More information about nutritional value of fruits and vegetables" and "More information about local recipe" because the respondents' feeling is that this can result to better cognitive engagement with the online organic brand.

\subsubsection{Affinity Diagramming}

Affinity diagram was deviced by a Japanese anthroplpgist Kawakita Jiro in the year 1960. This is also known as affinity chart or K-J Method (Foster, 2010). It is a tool to generate groups of data based on their natural relationship through brainstorming (Foster, 2010). Affinity diagramming is a participatory method where concepts written on cards or sticky notes are sorted into related groups and sub-groups (Courage \& Baxter, 2005). An affinity diagramming was done to determine how the users mentally organize the items into categories. Some broad categories have been identified from the literature and expert opinion and the new items which were generated from depth interview of the individuals followed by open coding or primary labeling were written on sticky notes which are sorted into categories as a workshop activity. 6 masters students from different disciplines in an institute were selected who were well informed and regular consumer of organic food and frequently purchase through an online platform.

The steps for affinity diagram which was conducted in this study were as follows

i). Record each of the items from the list of open coding on the sticky note.

ii). The broad category was plotted on a large sheet.

iii). All the team members were allotted 15 minutes to populate the sheet on related categories. Each member in the team was given a set of sticky notes which consists of all the items. iv). Then everyone in the team were individually allowed to move the sticky notes silently without discussion.

v). The maximum nu mber of votes for each of the items in a particular category were selected.

vi). Then draw the final affinity diagram.

The intension of this affinity diagramming was to diagnose the items which can explain the concepts by organizing the qualitative data generated through open coding.

\subsubsection{Axial Coding}

Axial Coding is the next phase after Open Coding as per grounded theory. Evolving hypotheses, and different relationship statements are created at conceptual abstract level and not directly from the raw data. These statements and hypotheses are then tested through other methods (Corb in, 1998). This process requires more conceptual clarity and abstraction at theoretical level. It also requires a sophis ticated coding technique, commonly termed as 'axial coding' as per Grounded Theory (Glaser and Strauss, 1967).

The abstract concepts encompass multiple tangible instances revealed from the data (Goulding, 2002). Various stages of data gathering, interpretation and analys is emp loys complex and sophisticated methods for theoretical coding. According to grounded theory analys is need to be raised at a more abstract level. Therefore, the concept is away from description and leads more towards theory development (Goulding, 2002). Here in this study one such concept is consumers' Cognitive Engagement (CE) which the researcher derived to be one of the driving factor for Consumers' Perceived Experiential Value (CPEV), Similarly Emotional Engagement (EE), Behavioral Engagement (BE), Telepresence (Tele), Willingness to co-create (WTC), Willingness to Pay for Experience (WPE), Ease of Use (EOU) are other driving factors of CPEV.

Here in this study the respondents or the participants in affinity diagramming workshop and the researcher felt that more trustworthy with better connectivity with the farmers, more trustworthy if source and vegetables and fruits can be tracked, more information about nutritional value of fru its and vegetables, more information about local recipe are related to consumers' cognitive engagement and which in turn can lead to Consumers' Perceived Experiential Value. Similarly, all the categories and sub categories (Table 1) were analyzed through axial coding. 
Table 1. Partial List of Categories and Sub- Categories

\begin{tabular}{|c|c|}
\hline Categories & Subcategories \\
\hline Cognitive Engagement (4) & $\begin{array}{l}\text { - More trust worthy with better connectivity with the farmers. } \\
\text { - } \quad \text { More trust worthy if source and veget ables and fruits can be tracked. } \\
\text { - } \quad \text { More information about nutritional value of fruits and vegetables. } \\
\text { More information about local recipe. }\end{array}$ \\
\hline Emotional Engagement (6) & $\begin{array}{l}\text { - I wish to get fresh organic vegetable/fruit through online store. } \\
\text { - I wish to be connected with the marginalized organic farmers and underst and their production } \\
\text { challenges. } \\
\text { - I wish to get more geographical information related to crop planning. } \\
\text { - I would love to get customized fresh local food from our indigenous small-scale food producers, } \\
\text { which is difficult to make at home. } \\
\text { - I feel, the need for local grown food produce seems to be fading out from customers' mind. } \\
\text { I wish for a better experience and engagement with local grown food and food produce. }\end{array}$ \\
\hline Behavioral Engagement (4) & $\begin{array}{l}\text { - I will better avoid online organic purchase, as I tend to buy more than my requirement. } \\
\text { - I am okay with late delivery if am sure about the quality of vegetable/fruit. } \\
\text { - I will be patient enough with irregular delivery of organic producers if I am convinced with their } \\
\text { supply chain challenges. } \\
\text { - I will be convinced with their late or irregular delivery if I can track their service touch points and } \\
\text { have a personalized connection with the producers. }\end{array}$ \\
\hline Telepresence (3) & $\begin{array}{l}\text { - I get deeply engaged with well-designed online st ore and tend to buy more. } \\
\text { - } \quad \text { I forget about my real need and spend lot of time on this attractive virtual st ore. } \\
\text { - } \quad \text { I feel my mind becomes fully engaged if the online store is well designed and at tractive. }\end{array}$ \\
\hline Ease of Use (4) & $\begin{array}{l}\text { - I can only buy through those online stores, which is simple and easy to navigate. } \\
\text { - } \quad \text { I can buy through those online stores where every steps are clear and understandable. } \\
\text { - It makes online shopping more easy if it provides necessary food information like nutritional value, } \\
\text { place where it is grown etc. } \\
\text { - I get more confused if too much information is provided. }\end{array}$ \\
\hline $\begin{array}{l}\text { Willingness to pay for } \\
\text { experience (5) }\end{array}$ & $\begin{array}{l}\text { - I will buy organic food even it is expensive. } \\
\text { - } \quad \text { I will engage and pay more for organic food if I get a clear understanding about their source. } \\
\text { - } \quad \text { I am ready to pay more if I feel I am more connected with the field and the farmers. } \\
\text { - } \quad \text { I will buy organic food over conventional food if there is a reliable online service. } \\
\text { - } \quad \text { I am ready to pay more on organic food if there is a continuous supply through an onlineplatform. }\end{array}$ \\
\hline $\begin{array}{l}\text { Willingness to co- create } \\
\text { (5) }\end{array}$ & $\begin{array}{l}\text { - Ready to engage more if I feel that I am more connected with the field and the farmers through this } \\
\text { online platform and can chat with them. } \\
\text { Love to purchase through a platform where I can place my demand and help the farmers for } \\
\text { effective crop planning. } \\
\text { - Like to form local customer group and help the organic food producers to resolve their supply chain } \\
\text { challenges. } \\
\text { Will be happy to own a kitchen garden in my apartment and grow some easy to maintain organic } \\
\text { vegetables/fruits. } \\
\text { Like to be a part of a community space where I can share my feedback and ideas on regular basis } \\
\text { and help the organic farmers. }\end{array}$ \\
\hline
\end{tabular}




\subsubsection{Selective Coding}

The categories and sub-categories were analy zed based on axial coding reflects that all the categories are linked to CPEV. The study from multiple depth interviews conducted among the consumers and the experts revealed that CPEV has some relation with consumers' cognitive, behavioral and emotional engagement, telepresence, willingness to co-create, ease of use and willingness to pay for experience. The categories and sub categories, which evolved through qualitative research, were partially listed in Table 1.

\subsection{Quantitative Research Method}

The items generated from qualitative research were used for questionnaire design and survey. An online survey was conducted across India. The questionnaire consists of 33 items and the respondents had to mark them in a 5-point scale with 1 as lowest level of agreement and 5 as highest level of agreement.

\subsubsection{Exploratory Factor Analys is (EFA)}

The initial phase of survey was conducted among 132 respondents. Out of which 129 responses were complete and used for analysis. EFA was conducted for dimension reduction and final item identification under each factor prior to Confirmatory Factor Analysis. The items which loaded equal to or more than 0.6 were used for further analysis. A new set of questionnaire was developed with 31 items and two items were dropped due to low factor loading. Total 618 data points were collected for second phase of data collection. Out of which 584 were complete and can be used for Confirmatory Factor Analysis.

\subsubsection{Confirmatory Factor Analysis (CFA)}

Structural Equations Modeling (SEM) was used to perform Confirmatory Factor Analysis. The tests were conducted for validity and reliability of the items generated for each constructs to measure CPEV (Hair et al., 2006). The fit indices for the measurement model related to Consumers' Perceived Experience Value are satisfactory (Table 2). Therefore, it can be inferred that the data fits the Model.

The advantage of CFA/SEM is its ability to assess the construct validity of a proposed measurement theory (Hair et al., 2006). The constructs were validated through Convergent and Discriminant Validity.

\subsubsection{Convergent and Discriminant Validity}

Construct Validity is measured through two indicators Convergent validity and Discriminant validity

\subsubsection{Convergent Validity (CV)}

Convergent Validity was tested through Factor Loadings, Average Variance Extracted (A VE) and Construct Reliability (CR) (Hair et al., 2006).

\subsubsection{Factor Loadings}

The standardized loading estimates as per the literature should be around 0.5 or higher and ideally 0.7 or higher (Hair et al., 2006). All the items have Standardized Loading Estimate above 0.5. And some of the $m$ are above 0.8 and 0.9 as shown in the Table 3

Table 2. Model Fit Indices of the Measurement Model (CPEV)

\begin{tabular}{|c|c|c|c|c|c|}
\hline Measurement Model & CMIN/DF & GFI & RMSEA & NFI & CFI \\
\hline $\begin{array}{c}\text { Consumers' Perceived } \\
\text { Experience Value (CPEV) }\end{array}$ & 4.008 & 0.911 & 0.072 & 0.914 & 0.943 \\
\hline Threshold(Hairet al. 2010) & $\begin{array}{c}<3 \text { good; }<5 \text { can be } \\
\text { accepted }\end{array}$ & $>0.95$ good & $\begin{array}{c}<0.05 \text { is good } \\
0.05-0.1 \text { is moderate }\end{array}$ & $\begin{array}{c}\text { ranges from } 0-1 \\
\text { with perfect fit } \\
\text { as 1 }\end{array}$ & $\begin{array}{c}>0.92 \text { when the } \\
\text { sample size is } \\
\text { more than 250 }\end{array}$ \\
\hline
\end{tabular}


Table 3. Standardized Loading Estimate (CPEV Measurement Model)

\begin{tabular}{|c|c|c|c|}
\hline \multicolumn{4}{|c|}{ Willingness to Pay for Experience(WPE) } \\
\hline WPE1 & $<---$ & WPE & .916 \\
\hline WPE2 & $<---$ & WPE & .992 \\
\hline WPE3 & $<---$ & WPE & .924 \\
\hline WPE4 & $<---$ & WPE & .849 \\
\hline WPE5 & <--- & WPE & .908 \\
\hline \multicolumn{4}{|c|}{ Cognitive Engagement (CE) } \\
\hline CE1 & $<---$ & $\mathrm{CE}$ & .990 \\
\hline CE2 & $<---$ & $\mathrm{CE}$ & .956 \\
\hline CE3 & $<---$ & $\mathrm{CE}$ & .926 \\
\hline CE4 & $<---$ & $\mathrm{CE}$ & .894 \\
\hline \multicolumn{4}{|c|}{ Emotional Engagement (EE) } \\
\hline EE1 & $<---$ & $\mathrm{EE}$ & .609 \\
\hline EE2 & <--- & $\mathrm{EE}$ & .626 \\
\hline EE3 & $<---$ & $\mathrm{EE}$ & .717 \\
\hline EE4 & $<---$ & $\mathrm{EE}$ & .710 \\
\hline EE5 & $\begin{array}{l}<-- \\
--\end{array}$ & $\mathrm{EE}$ & .618 \\
\hline EE6 & $<---$ & $\mathrm{EE}$ & .665 \\
\hline \multicolumn{4}{|c|}{ Behavioral Engagement } \\
\hline BE1 & <--- & $\mathrm{BE}$ & .904 \\
\hline BE2 & $<---$ & $\mathrm{BE}$ & .502 \\
\hline BE3 & $<--$ & $\mathrm{BE}$ & .972 \\
\hline BE4 & $<---$ & $\mathrm{BE}$ & .573 \\
\hline \multicolumn{4}{|c|}{ Telepresence } \\
\hline Tele1 & $<---$ & Tele & .884 \\
\hline Tele2 & $<---$ & Tele & .919 \\
\hline Tele 3 & $<---$ & Tele & .951 \\
\hline \multicolumn{4}{|c|}{ Willingness to Co-create } \\
\hline WTC1 & $<---$ & WTC & .831 \\
\hline WTC2 & $<---$ & WTC & .802 \\
\hline WTC3 & $<---$ & WTC & .844 \\
\hline WTC4 & $<---$ & WTC & .551 \\
\hline WTC5 & $<--$ & WTC & .591 \\
\hline \multicolumn{4}{|c|}{ Easy of use } \\
\hline EOU1 & <--- & $\mathrm{EOU}$ & .927 \\
\hline EOU2 & $<---$ & $\mathrm{EOU}$ & .966 \\
\hline EOU3 & $<---$ & EOU & .588 \\
\hline EOU4 & $\begin{array}{ll}<--- \\
\end{array}$ & EOU & .639 \\
\hline
\end{tabular}

\subsubsection{Average Variance Extracted (AVE)}

The AVE of all the constructs are given in Table 4 are higher than 0.5 except EE which is close to 0.5. This suggests adequate convergence (Hair et. al 2006).

\subsubsection{Construct Reliability (CR)}

$\mathrm{CR}$ is also an indicator of CV. An estimate of 0.7 or higher is suggestive of good reliability. If the construct reliability is high, then it signifies that there is an internal consistency existing with in the constructs. Therefore, this signifies that all the measures were consistent and representing the similar hidden construct (Hair et al., 2006). In Table 4 we see that the Construct Reliability of the factors are equal or above 0.7. This validates internal consistency and adequate convergence.

Table 4. AVE and CR of the factors

\begin{tabular}{|c|c|c|c|}
\hline & AVE & SQRT of AVE & CR \\
\hline WPE & 0.84443 & 0.91893 & 0.93189 \\
\hline CE & 0.88768 & 0.94217 & 0.95219 \\
\hline EE & 0.46418 & 0.65893 & 0.76619 \\
\hline BE & 0.58558 & 0.76523 & 0.80273 \\
\hline Tele & 0.84347 & 0.91841 & 0.90599 \\
\hline WTC & 0.53979 & 0.73471 & 0.80433 \\
\hline EOU & 0.63663 & 0.79789 & 0.82422 \\
\hline
\end{tabular}

\subsubsection{Discriminant Validity (DV)}

The extent to which the distinction between the construct exists is identified through Discriminant Validity indicator. For Discriminant valid ity, the square root of the Average Variance Extracted of each construct should be significantly greater than the correlation of the specific construct with any of the other constructs (Fornell and Larcker,1981). Also, the value for Average Variance Extracted related to each construct should be at least 0.5 (Fornell and Larcker, 1981). As square root AVEs satisfy the above condition shown in Table 5, the constructs possess DV. The only exception here is Emotional Engagement (EE) where the value of A VE is 0.46 which is close to 0.5 and can be even rounded up to 0.5 . And also the value of $\mathrm{CR}$ for that construct is 0.766 which is again above 0.7. Therefore, Emotional Engagement has been considered as a valid construct in this study. 
Table 5. Discriminant Validity

\begin{tabular}{|c|c|c|c|c|c|c|c|}
\hline & WPE & $\mathbf{C E}$ & $\mathbf{E E}$ & $\mathbf{B E}$ & Tele & WTC & EOU \\
\hline WPE & $\mathbf{0 . 9 1 8 9 3}$ & & & & & & \\
\hline CE & .071 & $\mathbf{0 . 9 4 2 1 7}$ & & & & & \\
\hline EE & .420 & .062 & $\mathbf{0 . 6 5 8 9 3}$ & & & & \\
\hline BE &. .005 & .323 & .141 & $\mathbf{0 . 7 6 5 2 3}$ & & & \\
\hline Tele & .185 & .022 & .377 & .064 & $\mathbf{0 . 9 1 8 4 1}$ & & \\
\hline WTC & .092 & .029 & .122 & -.040 & -.070 & $\mathbf{0 . 7 3 4 7 1}$ & \\
\hline EOU & .234 & .062 & .402 & .048 & .410 & .063 & $\mathbf{0 . 7 9 7 8 9}$ \\
\hline
\end{tabular}

\section{Conclusions}

The determinants or constructs that can drive Consumers' Perceived Experience Value were identified through Grounded Theory. The study also generated a set of items related to each of those constructs. For example, the items like "More trustworthy with better connectivity with the farmers", More trustworthy if the source of vegetables and fruits can be tracked, "Information about nutritional value of fruits and vegetables", "More information about local recipe" were mapped under a construct called Cognitive Engagement. Similarly, six items were mapped under Emotional Engagement, four items under Behavioral Engagement, three items under Telepresence, five items under Willingness to co-create, five items under Willingness to Pay for Experience and Four items under Ease of Use. All the items were explored in relation to online organic food purchase.

The items were generated through well-structured qualitative research methods like grounded theory and affinity diagramming. The items were validated through quantitative research like confirmatory factor analysis through structural equation modeling. The items can be used by the digital marketing team to measure the efficiency of an experience design for an online organic food store. The items will also facilitate them to measure consumers' engagement with the online platform through multiple dimensions.

\section{Contribution of the Study}

The study contributes a scale which can measure the constructs like Cognitive Engagement, Emotional Engagement, Behavioral Engagement, Telepresence, Willingness to co-create, Willingness to pay for Experience and Ease of Use in relation to online organic food purchase which was not available in the existing literature. A working definition for "Consumer Perceived Experience Value" in relation to online organic food purchase can be evolved around the determinants mentioned above. This will be beneficial for the organic food producers to develop a digital marketing strategy to penetrate the market. This study will also help the service and experience designers to explore this opportunity and create a platform for the small-scale farmers and contribute in their livelihood development.

\section{Acknowledgements}

The author truly grateful to all the respondents who spend their valuable time to fill the questionnaire. The author's sincere thanks goes to the experts and each individual for their time and supported to conduct a detailed depth interview.

\section{REFERENCES}

[1] Al-Sabbahy, Hesham Z., Yuksel Ekinci, and Michael Riley. "An Investigation of Perceived Value Dimensions: Implications for Hospitality Research.” Journal of Travel Research, 42 (3): 226-34, 2004.

[2] Chen, Ching-Fu, and Fu-Shian Chen. "Experience Quality, Perceived Value, Satisfaction and Behavior Intentions for Heritage Tourists." Tourism Management, 31 (1): 29-35, 2010.

[3] C. Courage, and K. Baxter. Understanding your users: A practical guide to user requirements methods, tools, and techniques. Gulf Professional Publishing, 2005.

[4] C. Fornell, and F. D. Larcker, "Evaluating structural equation models with unobservable variables and measurement error." Sage Publisher, Journal of marketing research, 18, no. 1, pp.39-50, 1981.

[5] C. Goulding, Christina. Grounded theory: A practical guide for management, business and market researchers. Sage Publication, 2002.

[6] C. Lavín, E. Alvaro, B. Diego and M. Sebastián, "What makes people decide to pay more? Understanding cooperation in the context of an alternative food network." Asian Journal of Social Psychology 18, no. 3, pp. 236-245, 2015.

[7] Dumand, Teoman, and Anna S. Mattila. "The Role of Affective Factors on Perceived Cruise Vacation Value." Tourism Management, 26 (3), 311-23, 2005. 
[8] F. S. Thomas, and K. K. Ganguly. Managing quality: Integrating the supply chain, Pearson Prentice Hall, New Jersy 2007.

[9] Glaser, Barney G., Anselm L. Strauss, and E. Strutzel. "The discovery of grounded theory: Strategies for qualitative research, Hawthorne, New York, 1967.

[10] J.F. Hair, W.C. Black, B.J. Babin, R.E. Anderson and R.L. Tatham, Multivariate Data Analysis, 6th ed., Pearson Education, Inc, 2006.

[11] J.M. Corbin, "Alternative interpretations: valid or not?" Theory \& Psychology, 8, no. 1, pp. 121-128, 1998.

[12] Kashyap, Rajiv, and David C. Bojanic. "A Structural Analysis of Value, Quality, and Price Perceptions of Business and Leisure Travelers." Journal of Travel Research, 39 (1): 45-51, 2000.

[13] L. Groeger, M. Lara and L.D. Hollebeek, "Capturing value from non-pay ing consumers' en gagement behaviours: field evidence and development of a theoretical model." Journal of Strategic Marketing 24, no. 3-4, pp. 190-209, 2016.

[14] L.D. Hollebeek, "Demy stify ing customer brand en gagement: Exploring the loyalty nexus." Journal of marketing management 27, no. 7-8, pp. 785-807, 2011b.

[15] L.D. Hollebeek, Linda. "Exploring customer brand engagement: definition and themes." Journal of strategic Marketing 19, no. 7, pp-555-573, 2011a.

[16] Mollen, Anne, and Hugh Wilson. "Engagement, telepresence and interactivity in online consumer experience: Reconciling scholastic and managerial perspectives. "Journal of business research 63, no. 9-10 pp. 919-925, 2010

[17] Nilson, Torsten H. Value-Added Marketing: Marketing Management for Superior Results. Berkshire, UK: McGraw-Hill, 1992.

[18] Ostrom, Amy, and Dawn Iacobucci. "Consumer Trade- Offs and the Evaluation of Services." Journal of Marketing, 59 (January): 17-28, 1995.

[19] Parry, Ken W. "How? and why? Theory emergence and using the grounded theory method to determine levels of analy sis." In Multi-level issues in organizational behavior and strategy, pp. 127-141. Emerald Group Publishing Limited, 2003.

[20] Petrick, James F. "The Roles of Quality, Value, and Satisfaction in Predicting Cruise Passengers' Behavioral Intentions." Journal of Travel Research, 42 (4), 397-407, 2004.

[21] Prebensen, N. K., Woo, E., Chen, J. S., \& Uysal, M. Motivation and involvement as antecedents of the perceived value of the destination experience. Journal of travel research, 52(2), 253-264, 2013.

[22] R.J. Brodie, L. D. Hollebeek, B. Jurić, and A. Ilić. "Customer engagement: Conceptual domain, fundamental propositions, and implications for research.", Sage Publisher, Journal of service research 14, no. 3 252-271, 2011.

[23] S. Ghosh, P. Barai, and B. Datta. "Identify Customer Involvement During Organic Food Purch ase Through FCB
Grid.", Taylor and Francis, Journal of International Food \& Agribusiness Marketing 31, no. 3, 237-254, 2019.

[24] So, Kevin Kam Fung, Ceridwyn King, and Beverley Sparks. "Customer engagement with tourism brands: Scale development and validation." Journal of Hospitality \& Tourism Research 38, no. 3 pp. 304-329, 2014.

[25] Tarkiainen, Anssi, and Sanna Sundqvist. "Product involvement in organic food consumption: does ideology meet practice?" Psychology \& Marketing 26, no. 9, pp. 844-863, 2009.

[26] Woodall, Tony, "Conceptualising Value for the Customer: An Attributional, Structural and Dispositional Analysis." Academy of Marketing Science Review, 12: 1-42, 1993

[27] Woodruff, Robert B. "Customer Value: The Next Source of Competitive Advantage." Journal of the Academy of Marketing Science, 25 (2):139-53, 1997 